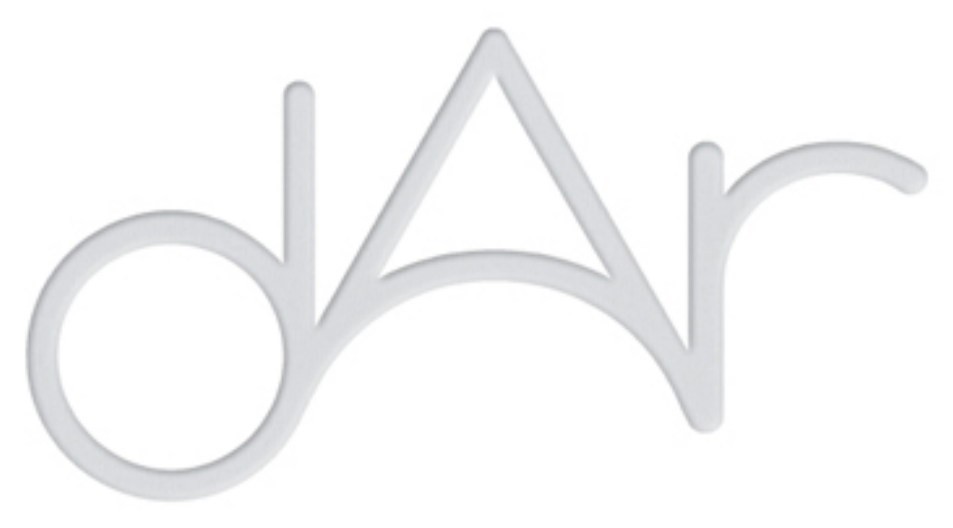

Caracterização das argamassas da muralha tardo-romana de Olisipo

Autor(es): $\quad$ Almeida, L.; Silva, A. Santos; Almeida, I. Moitinho

Publicado por: Imprensa da Universidade de Coimbra

URL

persistente: URI:http://hdl.handle.net/10316.2/43049

DOI: $\quad$ DOI:https://doi.org/10.14195/2182-844X_4_2

Accessed : $\quad$ 26-Apr-2023 09:09:06

A navegação consulta e descarregamento dos títulos inseridos nas Bibliotecas Digitais UC Digitalis, UC Pombalina e UC Impactum, pressupõem a aceitação plena e sem reservas dos Termos e Condições de Uso destas Bibliotecas Digitais, disponíveis em https://digitalis.uc.pt/pt-pt/termos.

Conforme exposto nos referidos Termos e Condições de Uso, o descarregamento de títulos de acesso restrito requer uma licença válida de autorização devendo o utilizador aceder ao(s) documento(s) a partir de um endereço de IP da instituição detentora da supramencionada licença.

Ao utilizador é apenas permitido o descarregamento para uso pessoal, pelo que o emprego do(s) título(s) descarregado(s) para outro fim, designadamente comercial, carece de autorização do respetivo autor ou editor da obra.

Na medida em que todas as obras da UC Digitalis se encontram protegidas pelo Código do Direito de Autor e Direitos Conexos e demais legislação aplicável, toda a cópia, parcial ou total, deste documento, nos casos em que é legalmente admitida, deverá conter ou fazer-se acompanhar por este aviso.

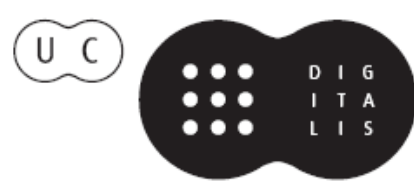



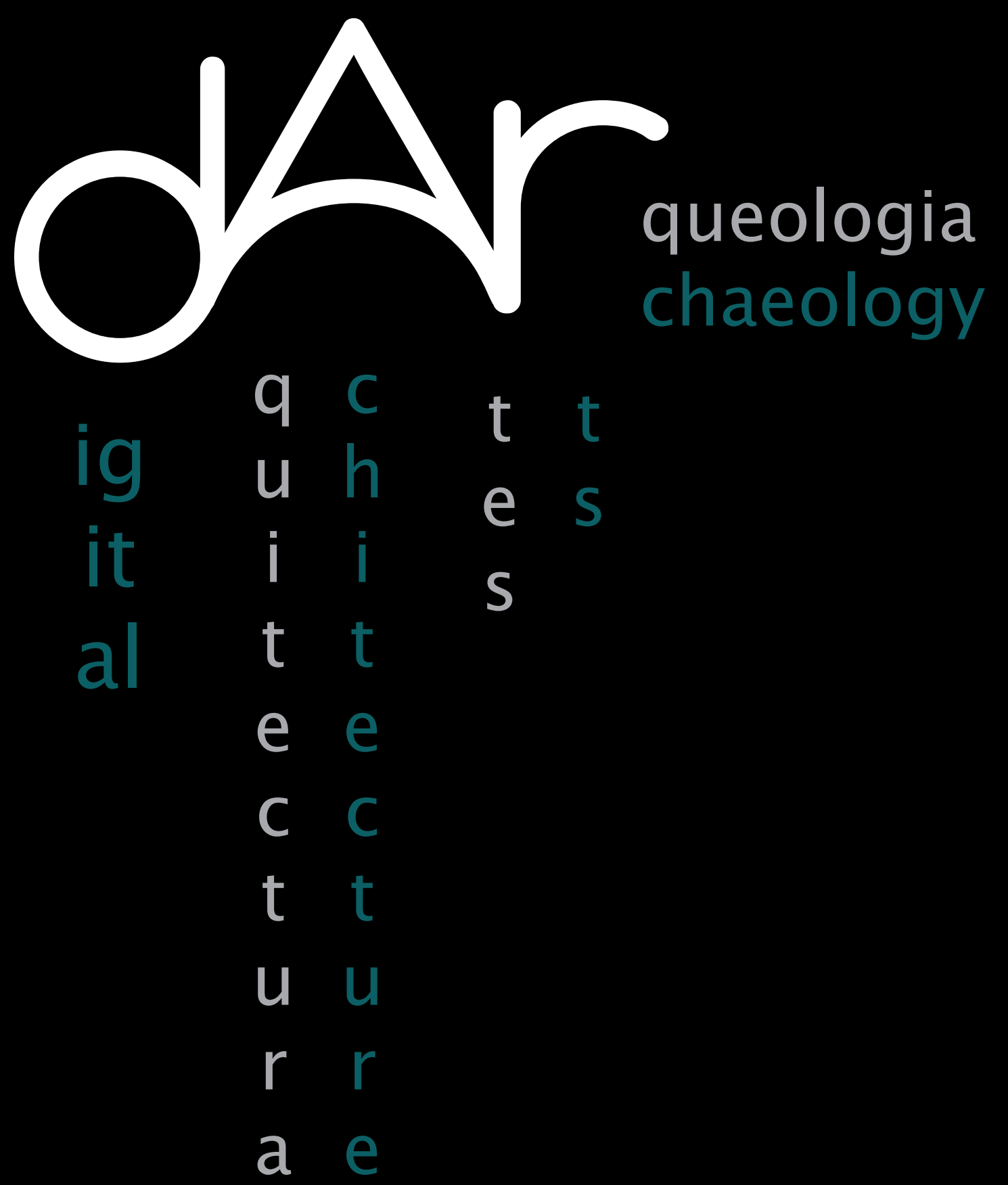

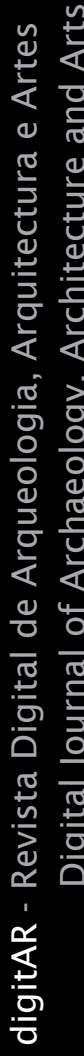

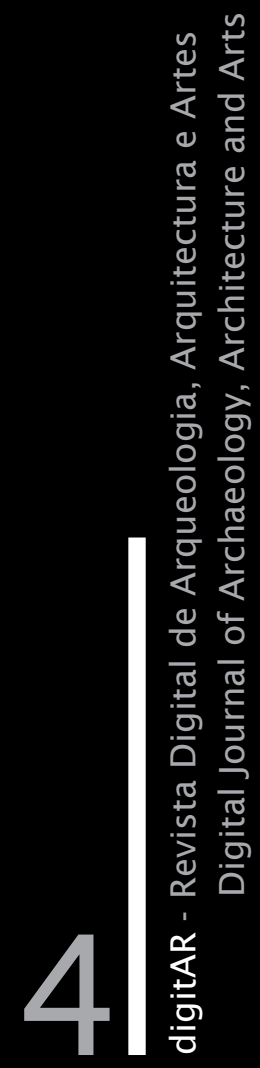




\section{MORTARS CHARACTERIZATION OF OLISIPO LATE ROMAN WALL}

\author{
L. Almeida* \\ Laboratório HERCULES, Universidade de Évora
}

\section{A. Santos Silva**}

Laboratório Nacional de Engenharia Civil (LNEC)

\author{
I. Moitinho de Almeida*** \\ IDL, Faculdade de Ciências, Universidade de Lisboa
}

\section{RESUMO}

No âmbito do Projecto Integrado de Estudo e Valorização da "Cerca Velha" de Lisboa, promovido pela Câmara Municipal de Lisboa desde o ano de 2009, foram realizadas várias intervenções arqueológicas que permitiram comprovar que o traçado deste equipamento defensivo remonta à época romana (Séculos I e finais do III - IV d. C.). Na sequência daquelas intervenções, que possibilitaram um levantamento rigoroso da estrutura tardo-romana de Olisipo de cronologia correlacionável com finais do séc. III e início do séc. IV d. C. foi realizado um trabalho de caracterização de argamassas daquela estrutura. Deste trabalho resultou a caracterização de amostras daqueles materiais visando a interpretação construtiva tipo-tecnológica, o esclarecimento de proveniências da matéria-prima utilizada e a análise do actual estado de conservação da estrutura nos locais amostrados, identificando os principais factores de degradação.

A metodologia utilizada compreendeu caracterizações granulométrica, mineralógica, química, petrográfica, física, mecânica e microestrutural. O trabalho contribuiu para o aumento do conhecimento das técnicas ancestrais de construção, numa perspetiva de conservação e restauro do património histórico-arquitectónico.

Palavras chave: Caracterização, Argamassa, Muralha, Romana, Lisboa.

*lotich@gmail.com

** ssilva@Inec.pt

\begin{abstract}
Since 2009 the City Hall of Lisbon has sponsored the study and valorization of the "Cerca Velha" (Old Rampart) of Lisbon, Portugal. The archaeological excavations done allowed checking the layout of the medieval Wall back to Roman times. These interventions enabled a partial mapping of the late Roman Olisipo's defensive wall correlated with the end of the $3^{\text {rd }}$ and the beginning of the $4^{\text {th }}$ century CE. This work presents the characterization of those construction materials in order to pursue an interpretation for standard construction technologies and to clarify the sources of raw materials used, as well as to identify potential degradation factors. The methodology used involves a comprehensive use of mechanical, physical, chemical, mineralogical and microstructural techniques. The results obtained contributed to increase the knowledge of the ancestral techniques in a perspective of conservation and restoration of historical and architectural heritage.
\end{abstract}

Key words: Characterization, Mortar, Wall, Roman, Lisbon

***imalmeida@fc.ul.pt 


\section{INTRODUÇÃO}

Promovido pela Câmara Municipal de Lisboa, o projecto de Estudo e Valorização da "Cerca Velha" de Lisboa, através do seu Centro de Arqueologia, permitiu comprovar que o traçado da estrutura defensiva remonta à época romana. Foram realizadas sondagens arqueológicas pontuais, colmatadas após registo e recolha de elementos utilizando uma estratégia de minimização de impactos arqueológicos.

Através de uma abordagem metodológica que compreendeu uma exaustiva utilização de técnicas analíticas complementares, este trabalho pretendeu relacionar diferentes funcionalidades da estrutura com as tecnologias de construção, através da análise das razões agregado/ligante das argamassas e apontar eventuais proveniências de matérias-primas, incluindo a natureza e a composição dos agregados e do ligante. Atendendo ao facto da "Cerca Velha" possuir uma vasta dispersão cronológica construtiva e com o objectivo de comparar técnicas construtivas de dois períodos distintos, foi incluído neste trabalho a caracterização de uma amostra de argamassa de uma estrutura de muralha Romana de cronologia Alto-Imperial (séc. I a II d.C.) (Carvalhinhos \& Mota 2013).

\section{ENQUADRAMENTO GEOGRÁFICO E GEOLÓGICO}

A zona de implantação da muralha situa-se na encosta sul da colina de S. Jorge, na Freguesia de Santa Maria Maior.

Do ponto de vista geológico, a encosta foi talhada em rochas detríticas e carbonatadas do Miocénico, constituídas por alternâncias de argilas e siltes com níveis margosos, calcários e calcários margosos com conteúdos variáveis em areia e areias finas frequentemente micáceas, sobre as quais assentam aluviões, nas zonas altimétricas mais baixas (Almeida 1986).

\section{METODOLOGIA EXPERIMENTAL 3.1. Amostragem}

Foram recolhidas amostras de argamassas do interior (núcleo) e do exterior (juntas entre silhares) das estruturas intervencionadas, assim como das suas fundações (embasamentos). A fig. 1 apresenta uma representação da "Cerca Velha" com identificação dos locais amostrados. A identificação das amostras, tipologia, localização, unidade estratigráfica e período histórico construtivo são apresentados na tabela 1 .

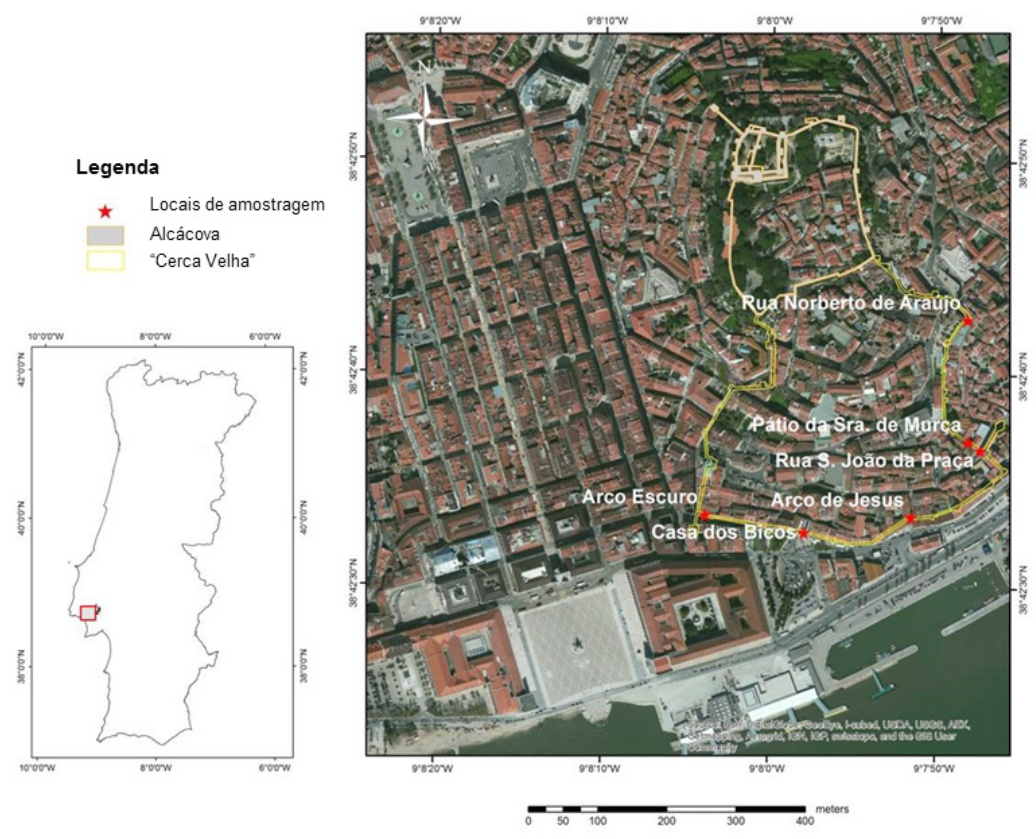

Figura 1-Traçado da "Alcáçova" e da "Cerca Velha" (adaptado de Silva, 1939) com localização dos locais amostrados. 
Tabela 1- Identificação e características das amostras

\begin{tabular}{lllll}
\hline Amostra & Tipologia & Localização & $\begin{array}{l}\text { Unidade } \\
\text { Estratigráfica }\end{array}$ & $\begin{array}{l}\text { Período } \\
\text { Histórico }\end{array}$ \\
\hline AE1 & Argamassa de cal (interior) & Arco Escuro & UE15 & Tardo-romano \\
AE2 & Argamassa de cal (junta) & Arco Escuro & UE50 & Tardo-romano \\
CDB1 & Argamassa de cal (interior) & Casa dos Bicos & UE20 & Tardo-romano \\
CDB2 & Argamassa de cal (interior) & Casa dos Bicos & UE20 & Tardo-romano \\
CDB3 & Argamassa de terra (junta) & Casa dos Bicos & UE380 & Tardo-romano \\
CDB4 & Argamassa de terra (junta) & Casa dos Bicos & UE381 & Tardo-romano \\
ADJ1 & Argamassa de cal (embasamento) & Arco de Jesus & UE47 & Tardo-romano \\
ADJ2 & Argamassa de cal (interior) & Arco de Jesus & UE32 & Tardo-romano \\
SJP1 & Argamassa de cal (embasamento) & S. João da Praça & UE79 & Tardo-romano \\
SJP2 & Argamassa de cal (junta) & S. João da Praça & UE140 & Tardo-romano \\
PSM1 & Argamassa de cal (embasamento) & Pátio Sra. Murça & UE81 & Tardo-romano \\
PSM2 & Argamassa de cal (junta) & Pátio Sra. Murça & UE80 & Tardo-romano \\
RNA1 & Argamassa de cal (embasamento) & R. Norberto Araújo & UE228 & Alto-Imperial \\
\hline
\end{tabular}

\subsection{Caracterização}

A metodologia de caracterização utilizada envolveu o exame macroscópico e microestrutural das amostras, a análise granulométrica e mineralógica do agregado, a análise química de alguns componentes das pastas, absorção capilar e a resistência à compressão das argamassas. A análise mineralógica foi obtida por difracção de raios X (DRX), usando a radiação CoKa com filtro de $\mathrm{Fe}$ com uma velocidade de varrimento $0,05 \% \mathrm{~s}$ entre $3^{\circ}$ a $74^{\circ} 2 \theta$. Para DRX foram analisadas dois tipos de fracções: uma fracção correspondente à argamassa tal qual (fracção global) e obtida por moagem após desagregação da argamassa, e uma fracção designada de fracção fina, enriquecida em ligante, e obtida a partir do material fino desagregado e de granulometria inferior a $0,106 \mathrm{~mm}$. A fracção global de cada amostra foi também utilizada para a análise termogravimétrica e térmica diferencial (ATG-ATD) e química (via húmida por digestão em ácido clorídrico ou nítrico). A ATG-ATD foi realizada sob uma atmosfera de árgon, a uma taxa de aquecimento de $10^{\circ} \mathrm{C} /$ min desde a temperatura ambiente até $1000^{\circ} \mathrm{C}$. As análises térmica e química foram realizadas para determinar a razão agregado/ligante (traço) suportadas por análises petrográficas modais. Para petrografia, prepararam-se lâminas delgadas, que foram obtidas após a impregnação das argamassas sob vácuo com uma resina epóxi, desbastadas e polidas com abrasivos próprios. A distribuição do tamanho das partículas dos agregados foi obtida a partir da separação por peneiração do resíduo insolúvel após ataque ácido ( $\mathrm{HCl}$ a $14 \%)$. Uma vez que as amostras apresentavam um conteúdo elevado de conchas de bivalves, a digestão ácida foi realizada em etapas faseadas para minimizar o ataque dos agregados carbonatados. Para a análise química dos componentes do ligante, efetuou-se o ataque com ácido nítrico diluído (1:10) a quente. $\mathrm{Na}$ fracção solúvel foi avaliado o teor de álcalis (expresso em termos de óxidos de sódio e potássio) por espetrofotometria de absorção atómica, de cloretos por potenciometria e de sulfatos e sílica solúvel por gravimetria. O resíduo insolúvel foi pesado e peneirado para determinar a distribuição granulométrica dos agregados. As observações da microestrutura foram efetuadas em superfícies recémfraturadas por microscopia eletrónica de 


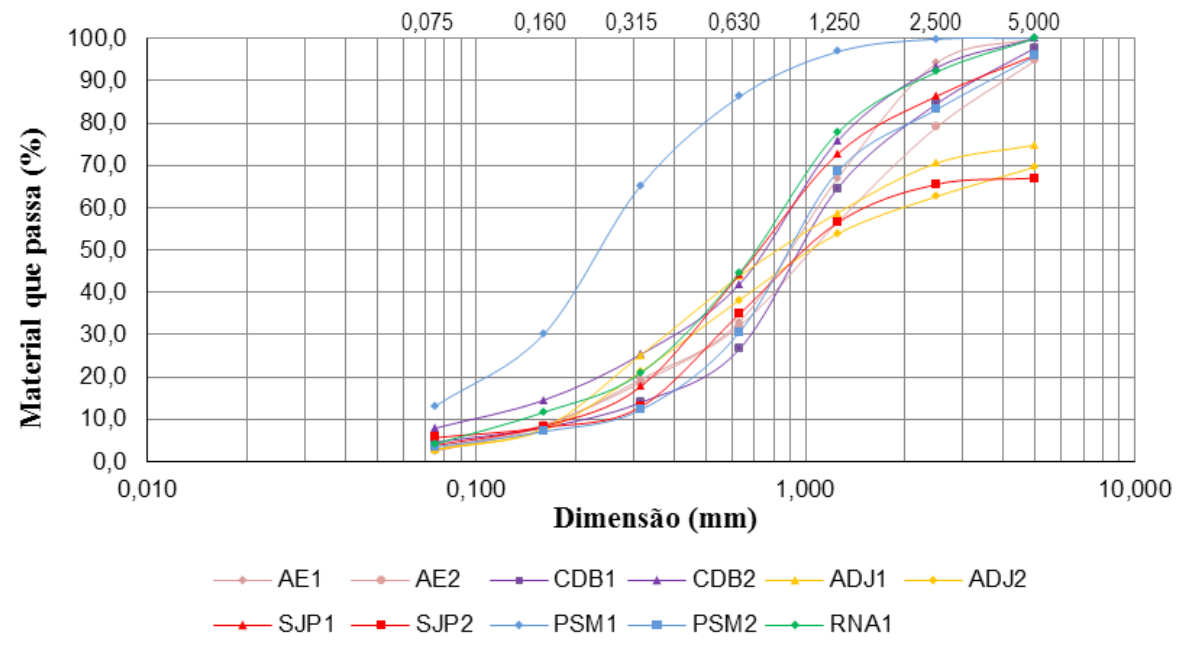

Fig. 2 Distribuição granulométrica do agregado das amostras analisadas

varrimento (MEV) com análise elementar através de um espetrómetro de raios $X$ por dispersão de energias (EDS). Para avaliar o comportamento à absorção de água por capilaridade (Veiga et al 2004), a face externa de um fragmento plano da amostra foi colocada em contacto com água utilizando um recipiente constituído por um cesto de arame e gaze geotêxtil. A amostra foi pesada periodicamente para determinar o ganho de água ao longo de 24 h. Para o ensaio de resistência à compressão, as amostras foram confinadas com uma argamassa que permitiu obter uma forma regular e necessária para a adaptação ao equipamento de compressão utilizado segundo a norma EN 1015-11 (European Committee of Standardization - CEN, 1999).

\section{RESULTADOS E DISCUSSÃO 4.1 Distribuição granulométrica dos agregados}

A fig. 2 apresenta a distribuição granulométrica dos agregados das amostras estudadas. As amostras de argamassas de terra foram excluídas, uma vez que não podiam ser comparadas tipologicamente com as restantes. Estas, aliás, foram exclusivamente estudadas do ponto de vista mineralógico, com vista a conhecer a natureza dos seus constituintes.
A análise granulométrica evidenciou que a fracção predominante na maioria das amostras está situada entre 1,25 mm e 0,630 mm. Globalmente mais de $55 \%$ dos agregados estão situados nas classes granulométricas que correspondem dimensionalmente a areias grosseiras e balastros.

\subsection{Composição mineralógica e análise petrográfica}

Os resultados de DRX mostram que as argamassas são essencialmente constituídas por quartzo e calcite, com uma sobreposição da calcite em relação ao quartzo na fracção fina, sugerindo a utilização de cal aérea de composição calcítica como ligante. As amostras CDB3 e CDB4 (argamassas de terra) não apresentam compostos carbonatados, enquanto nas amostras ADJl e AEl foi identificada a presença de montmorilonite. A caracterização petrográfica (Fig. 3) demonstrou aspetos texturais semelhantes entre as amostras, com ocorrência de agregados siliciosos distribuídos de forma homogénea e conchas carbonatadas roladas, essencialmente de bivalves, além de nódulos de cal e fragmentos cerâmicos sub-rolados, substâncias de neoformação maioritariamente associadas a agregados alterados e uma 

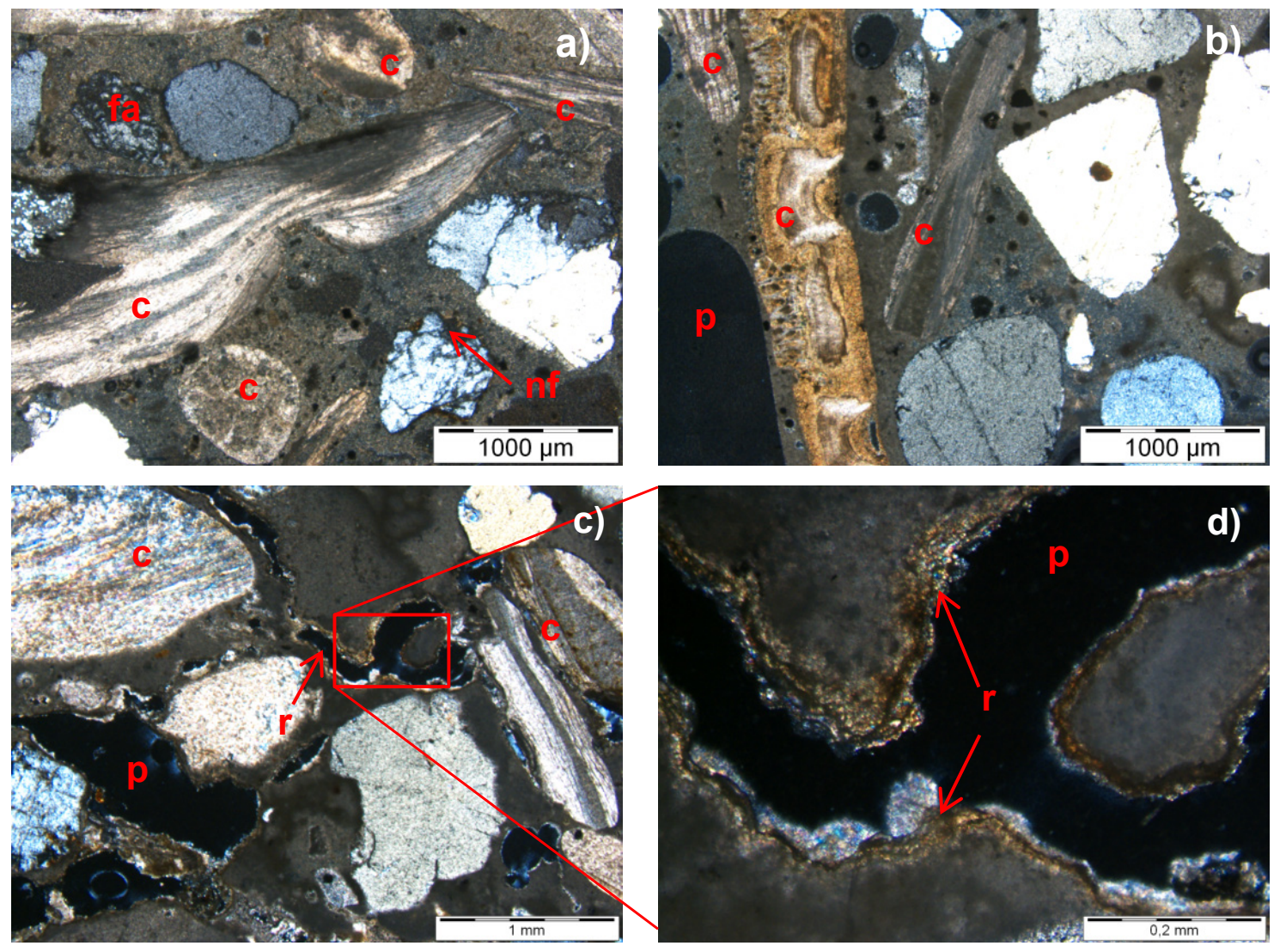

Figura 3- Aspetos petrográficos da amostra CDB1 em nicóis cruzados: c - Concha; fa - feldspato alcalino; $q$ - quartzo; p - poro; $n f$ - compostos de neoformação; $r$ - fase de recristalização.

recorrente precipitação de carbonatos nos bordos dos poros e microfissuras. Da análise modal por contagem de pontos ao microscópio petrográfico foi possível estimar as frequências relativas dos principais constituintes mineralógicos das argamassas, produzindo um acréscimo de rigor no cálculo do traço. A presença de conchas de bivalves, bem como o grau de arredondamento dos agregados sugere que o ambiente fluvio-estuarino fosse uma das fontes de matériasprimas, o que seria de esperar dada a proximidade da zona de implantação da muralha com os sedimentos aluviais.

\subsection{Análise térmica e química}

Os termogramas obtidos são típicos de argamassas de ligantes aéreos calcíticos, com uma considerável perda de massa no intervalo de temperaturas entre $600^{\circ} \mathrm{C}$ e $850^{\circ} \mathrm{C}$. De salientar os valores elevados de perda de massa na gama entre 25 e 120 - $C$ para as amostras AEl e ADJ1, que se atribui à presença de montmorilonite. As baixas concentrações em sílica solúvel e em álcalis indicam que não foram utilizados ligantes hidráulicos. No entanto, a maior concentração de álcalis e sais obtida nas amostras CDB1 e CDB2, deverá estar associada à contaminação induzida 
por uma laje moderna de betão que cobria o topo da estrutura tardo-romana.

\subsection{Caracterização física e mecânica} As amostras AEl, CDB1, ADJ2 e PSMl evidenciaram velocidades de absorção de água por capilaridade compatíveis com os resultados de argamassas antigas em bom estado de conservação (Veiga et all 2004). O pior comportamento foi registado pela amostra ADJ1. Esta amostra possui, por outro lado, a mais elevada resistência à compressão $\left(1,61 \mathrm{Nmm}^{-2}\right)$, refletindo uma provável ocorrência de componentes hidráulicos de neoformação. Em oposição, a amostra CDB2 possui uma baixa resistência à compressão causada pela presença combinada de sulfatos e de álcalis. A amostra ADJ2 mostrou ser aquela que se encontra em pior estado de conservação, uma vez que apresentou uma baixa resistência à compressão $\left(0.46 \mathrm{Nmm}^{-2}\right) \mathrm{e}$ absorção de água elevada após 24 horas.

\subsection{Análise microestrutural}

As características mais notáveis que se destacam através da análise por MEV/EDS são a presença de silicatos de alumínio e de cálcio presentes nas interfaces agregado/ligante, assim como depósitos de carbonato de cálcio revestindo os limites dos poros e microfissuras, indicando fenómenos de dissolução e consequente cristalização por processos de precipitação. A amostra ADJ1 apresenta estas ocorrências, o que parece explicar a sua elevada resistência mecânica à compressão. Outra característica observada diz respeito à composição elementar da matriz ligante, que apresenta quantidades elevadas de cálcio e carbono. Esta característica é consistente com a utilização de um ligante calcítico aéreo.

\subsection{Composições simplificadas e traço das argamassas}

As composições simplificadas (tabela 2) foram calculadas através do método proposto por Jedrzejewska, 1960. Este método combina o teor em carbonato de cálcio obtido por ATG com o teor do resíduo insolúvel obtido através da análise química. São, portanto, considerados três tipos de componentes: "carbonatos" (ligante), "fracção solúvel" (compostos solúveis em ácido sem formação de dióxido de carbono) e "agregados" (estimados por análise petrográfica modal,

Tabela 2- Composição simplificada e traço das argamassas

\begin{tabular}{|c|c|c|c|c|c|}
\hline \multirow[b]{2}{*}{ Amostra } & \multicolumn{4}{|c|}{ Composição simplificada (\% mássica) } & \multirow[t]{2}{*}{$\operatorname{Traço(3)}$} \\
\hline & $\begin{array}{l}\text { Agregados } \\
\text { siliciosos (1) }\end{array}$ & $\begin{array}{l}\text { Agregados } \\
\text { carbonatados }\end{array}$ & $\begin{array}{l}\text { Ligante } \\
\text { calcítico }\end{array}$ & Fracção solúvel (2) & \\
\hline $\mathrm{AEl}$ & 39 & 20 & 36 & 5 & $1,5: 0,7: 1,0$ \\
\hline AE2 & 41 & 12 & 44 & 2 & $1,2: 0,4: 1,0$ \\
\hline $\mathrm{CDB} 1$ & 42 & 23 & 31 & 5 & $1,8: 1,0: 1,0$ \\
\hline CDB2 & 41 & 32 & 22 & 4 & $2,5: 2,0: 1,0$ \\
\hline ADJI & 69 & 7 & 17 & 7 & $5,6: 0,6: 1,0$ \\
\hline ADJ2 & 53 & 24 & 19 & 4 & $3,9: 1,8: 1,0$ \\
\hline SJP1 & 50 & 2 & 44 & 5 & $1,6: 0,1: 1,0$ \\
\hline SJP2 & 43 & 42 & 12 & 4 & $5,0: 4,9: 1,0$ \\
\hline PSMI & 52 & 6 & 38 & 4 & $1,8: 0,2: 1,0$ \\
\hline PSM2 & 58 & 7 & 30 & 6 & $2,6: 0,3: 1,0$ \\
\hline RNAl & 61 & 5 & 29 & 5 & $2,9: 0,2: 1,0$ \\
\hline
\end{tabular}

(1) Inclui fragmentos cerâmicos; (2) Fração Solúvel = $100-\Sigma$ (Agregados); (3) Relação ponderal agregados siliciosos: agregados carbonatados : cal hidratada 
convertendo o volume ocupado pelos constituintes em percentagem mássica). Para o cálculo do traço das argamassas a calcite foi convertida em portlandite, de modo a obter o conteúdo em cal hidratada.

\section{CONCLUSÕES}

A ausência de ligantes hidráulicos e de carbonatos magnesianos na pasta de ligante é consistente com a utilização de cal aérea calcítica no fabrico de todas as argamassas, com exceção das argamassas de terra CDB3 e CDB4. O baixo teor em cloretos e sulfatos é compatível com a utilização de areias de ambientes de transição fluvioestuarinos, com concentrações de sais baixas a intermédias. Esta evidência é também corroborada pelas observações composicionais e morfológicas dos agregados. A proximidade da muralha com a margem fluvial do Rio Tejo sugere que os sedimentos aluvionares tenham sido privilegiados na utilização dos agregados. A cal, no entanto, deverá ter tido origem em calcários mais puros, com fracções detríticas inferiores aos calcários miocénicos que marcam presença na área de implantação da muralha. Assim, propõe-se que a fonte de extracção dos calcários tenha sido afastada da zona de construção da estrutura defensiva. A amostra RNAl (argamassa de cronologia alto-imperial) não apresenta propriedades composicionais distintivas das restantes amostras de cronologia tardo-romana, pelo que se levanta a questão se as técnicas construtivas se terão alterado durante aquele intervalo de tempo. Os traços das argamassas, a granulometria dos agregados e a microestrutura não permitem estabelecer uma relação unívoca entre características tipológicas e funcionais das argamassas aplicadas a cada estrutura. Por este motivo não é possível afirmar, por exemplo, que todas as argamassas dos embasamentos (ou de outra zona da muralha) possuam características iguais entre si ou diferentes entre as outras, nas demais funcionalidades.

\section{AGRADECIMENTOS}

Os autores agradecem ao Centro de Arqueologia de Lisboa, em particular aos arqueólogos Manuela Leitão e Vasco Leitão, pela cedência de elementos e estreita colaboração, fundamentais à persecução dos objectivos alcançados neste trabalho.

\section{BIBLIOGRAFIA}

Carvalhinhos M. \& Mota N. 2013. Intervenção arqueológica urbana na Rua Norberto de Araújo, 21-29 (São Miguel, Lisboa). (NA 21 29) Relatório final. Centro de Arqueologia de Lisboa, Câmara Municipal de Lisboa.

Almeida F.M. 1986. Carta Geológica do Concelho de Lisboa e Notícia Explicativa da Carta Geológica do Concelho de Lisboa, Serviços Geológicos de Portugal, Lisboa.

Silva A.V. 1939. A Cerca Moura de Lisboa. Lisboa. Câmara Municipal.

Veiga M.R., Magalhães A.C. \& Bokan-Bosilikov V. 2004. "Capillarity tests on historic mortar samples extracted from site. Methodology and compared results". 13th International Brick and Block Masonry Conference. Amsterdam. Ed. LNEC. Lisboa.

European Committee of Standardization - CEN, 1999. Methods of test for mortar for masonry - Part 11: Determination of flexural and compressive strength of hardened rendering mortar, Brussels, EN 1015-11.

Jedrzejewska H., 1960. Old mortars in Poland: a new method of investigation. Studies in Conservation 5, 132-138. 